\title{
Chronic disease co-morbidity of asthma and unscheduled asthma care among adults: results of the national telephone health interview survey German Health Update (GEDA) 2009 and 2010
}

\author{
${ }^{*}$ Henriette Steppuhn ${ }^{1,2}$, Ute Langen ${ }^{1}$, Thomas Keil ${ }^{2,3}$, Christa Scheidt-Nave ${ }^{1}$ \\ ' Department of Epidemiology and Health Monitoring, Robert Koch Institute Berlin, Berlin, Germany \\ 2 Institute for Social Medicine, Epidemiology, and Health Economics, Charité - Universitätmedizin Berlin, Berlin, Germany \\ ${ }^{3}$ Institute of Clinical Epidemiology and Biometry, University of Würzburg, Würzburg, Germany
}

Received 16th April 2013; revised 8th September 2013; accepted 4th November 2013; online 18th December 2013

\begin{abstract}
Background: Co-morbidities may complicate the clinical management of chronic conditions such as asthma.

Aims: To quantify the strength of the relationship between asthma and other chronic diseases and to analyse whether co-morbidities contribute to unscheduled asthma care.

Methods: Data from two consecutive national telephone health interview surveys (GEDA 2009 and 2010) including a total of 43,312 adults ( $\geq 18$ years of age) were analysed. Persons with and without a current diagnosis of asthma were compared with respect to concurrent diagnoses (diabetes mellitus, hypertension, chronic heart failure, depression, osteoarthritis, stroke, coronary heart disease, and cancer). Logistic regression models were applied to assess the strength of the association between asthma and co-morbidities in the total study population and, among persons with asthma, between the number of co-morbidities and unscheduled inpatient (hospital admissions and/or emergency department admissions) or outpatient asthma care in the past 12 months.

Results: Overall, $5.3 \%(95 \% \mathrm{Cl} 5.0 \%$ to $5.6 \%)$ of adults reported current physician-diagnosed asthma. Asthma was significantly associated with most of the conditions considered and $18 \%$ of persons with asthma had three or more co-morbidities. Adjusted odds ratios (AOR) of unscheduled asthma care increased with numbers of conditions, with AOR 3.40 (95\% CI 1.39 to 8.31 ) for unscheduled inpatient care and AOR $2.32(95 \% \mathrm{Cl} 1.30$ to 4.14$)$ for unscheduled outpatient care comparing those with three or more co-morbidities versus those with none.

Conclusions: The magnitude of chronic disease co-morbidity is substantial in asthma, is related to unscheduled asthma care, and implies a significant number of adults with asthma facing complex healthcare needs.

(C) 2014 Primary Care Respiratory Society UK. All rights reserved.

H Steppuhn et al. Prim Care Respir J 2014; 23(1): 22-29

http://dx.doi.org/10.4104/pcrj.2013.00107
\end{abstract}

Keywords asthma, survey, healthcare utilisation, management, co-morbidity

\section{See linked editorial by Mercer on pg 4}

The full version of this paper, with online appendix,

is available online at www.thepcrj.org

\section{Background}

Co-morbidity - the presence of concomitant health conditions in individuals with an index disease - may complicate the clinical course and treatment of patients with the index disease. ${ }^{1}$ Previous studies have demonstrated that co-morbidity can have an adverse impact on patients' health-related quality of life (HRQoL) and can increase the socio-economic burden of chronic conditions on the healthcare system. ${ }^{1,2}$

Although asthma is a chronic disease that is highly relevant both to the individual and with regard to public health, published data covering a range of co-morbidities in the general population of

\footnotetext{
* Corresponding author: Miss Henriette Steppuhn, Department of Epidemiology and Health Monitoring, Robert Koch Institute Berlin, General-Pape-Strasse 62-66, D-12101, Berlin, Germany. Tel: +49 (0)30-7854-3384 Fax: +49 (0)30-18754-3211 E-mail: steppuhnh@rki.de
} 
adults with and without asthma are few. The data available suggest associations between asthma and major chronic conditions such as hypertension, diabetes, coronary heart disease, chronic heart failure, or malignancies that are not commonly recognised as co-morbidities typical of patients with asthma. ${ }^{3}$ Previous reports, however, have mainly been based on administrative data, ${ }^{4 \cdot 7}$ which do not permit adjustment for potential confounders such as socio-demographic factors or health-related behaviours.

Moreover, few studies have so far addressed the consequences of co-morbidities for health outcomes and healthcare among adults with asthma. Two previous analyses of population-based data suggested an adverse effect of major chronic conditions on usual activity levels as well as on general and disease-specific HRQoL. ${ }^{8,9}$ When comparing adults with and without asthma, co-morbidity was found to be associated with a significant proportion of overall hospitalisations, emergency room visits, and ambulatory care visits based on administrative health data. ${ }^{5}$ In an analysis of data from a large national health survey, Zhang et al. reported that persons with asthma who had at least one concurrent major chronic condition had a significantly higher chance to have experienced asthma symptoms and/or acute asthma attacks in the past year than those with no concurrent major chronic conditions. ${ }^{10}$ These authors also addressed the relevance of further research on the influence of major chronic conditions on asthma-related hospitalisations, emergency department (ED) visits, and physician visits.

Against this background, we used nationally representative health survey data of adults in Germany to quantify the strength of the association between asthma and eight other chronic conditions selected for their high prevalence and/or high impact on the healthcare system. ${ }^{11,12}$ We further analysed the influence of comorbidity on unscheduled inpatient and outpatient asthma care among adults with asthma.

\section{Methods}

\section{Study design and study population}

German Health Update (GEDA) is a periodically repeated national telephone health interview survey of adults ( $\geq 18$ years of age). ${ }^{13}$ The target population of these cross-sectional studies consists of all adults who live in private households with a landline telephone and who can fluently speak and understand German. A two-stage sampling procedure was used..$^{14,15}$ For sampling at the household level, the Gabler-Häder method ${ }^{16}$ was applied to randomly generate a pool of about 220,000 telephone numbers from complete listings of landline telephone extensions ${ }^{14,15}$ while, for random sampling at the individual level, the 'last birthday method' was used..$^{17}$ The study was approved by the Federal Commissioner for Data Protection and Freedom of Information and verbal informed consent had been received from all participants prior to the interview.

Between July 2008 and June 2009 and between September 2009 and July 2010, respectively, 21,262 persons and 22,050 persons completed the telephone interview. The cooperation rate at the individual level, which represents the cooperation rate at the respondent level, ${ }^{18}$ was $51.2 \%$ for GEDA 2009 and 55.8\% for GEDA $2010 .^{14,15}$
Table 1. Main characteristics of survey participants in the pooled sample of the German Health Update (GEDA) 2009 and 2010 surveys, the total sample of the GEDA 2010 survey, and among participants of the GEDA 2010 survey with current self-reported physiciandiagnosed asthma

\begin{tabular}{|c|c|c|c|}
\hline Characteristics & $\begin{array}{l}\text { Pooled } \\
\text { sample of } \\
\text { GEDA } 2009 \\
\text { and } 2010 \\
(\mathrm{~N}=43,312)\end{array}$ & $\begin{array}{l}\text { Total } \\
\text { sample } \\
\text { of GEDA } \\
2010 \\
(\mathrm{~N}=22,050)\end{array}$ & $\begin{array}{l}\text { Current } \\
\text { asthma } \\
\text { population } \\
\text { in GEDA } \\
2010 \\
(\mathrm{~N}=1,136)\end{array}$ \\
\hline \multicolumn{4}{|l|}{ Gender } \\
\hline Women, \% (n) & $51.5(24,597)$ & $51.5(12,483)$ & $61.1(737)$ \\
\hline \multicolumn{4}{|l|}{ Age, in years } \\
\hline Mean (SD) & $49.0(17.9)$ & $49.0(17.9)$ & $52.1(18.2)$ \\
\hline Range & $18-100$ & $18-99$ & $18-95$ \\
\hline \multicolumn{4}{|l|}{ Age groups, \% (n) } \\
\hline $18-29$ years & $17.1(7,620)$ & $16.9(3,831)$ & $13.4(171)$ \\
\hline $30-44$ years & $25.7(12,072)$ & $25.9(6,096)$ & $21.5(276)$ \\
\hline $45-64$ years & $32.7(15,441)$ & $32.7(7,980)$ & $35.3(440)$ \\
\hline$\geq 65$ years & $24.5(8,179)$ & $24.4(4,143)$ & $29.8(249)$ \\
\hline \multicolumn{4}{|l|}{ BMI status, \% (n) } \\
\hline$<25 \mathrm{~kg} / \mathrm{m}^{2}$ & $47.9(22,324)$ & $47.8(11,322)$ & $39.3(488)$ \\
\hline $25-<30 \mathrm{~kg} / \mathrm{m}^{2}$ & $36.2(14,383)$ & $36.3(7,338)$ & $36.7(387)$ \\
\hline$\geq 30 \mathrm{~kg} / \mathrm{m}^{2}$ & $15.9(5,722)$ & $15.8(2,931)$ & $24.0(237)$ \\
\hline \multicolumn{4}{|l|}{ Educational attainment, \% ( $\mathrm{n}$ ) } \\
\hline Primary & $22.1(4,210)$ & $22.1(2,082)$ & $27.1(126)$ \\
\hline Middle & $55.6(21,976)$ & $55.5(11,076)$ & $55.7(625)$ \\
\hline High & $22.3(17,063)$ & $22.3(8,865)$ & $17.3(384)$ \\
\hline \multicolumn{4}{|l|}{ Smoking status, \% (n) } \\
\hline Current & $29.8(12,514)$ & $30.0(6,291)$ & $29.7(322)$ \\
\hline Former & $26.3(11,409)$ & $26.6(5,881)$ & $31.0(338)$ \\
\hline Never & $43.9(19,373)$ & $43.4(9,873)$ & $39.3(476)$ \\
\hline \multicolumn{4}{|l|}{ Health condition, \% (n) } \\
\hline Diabetes mellitus & $7.4(2,477)$ & $7.4(1,262)$ & $10.7(92)$ \\
\hline Hypertension & $26.5(9,999)$ & $26.7(5,136)$ & $37.7(368)$ \\
\hline Coronary heart disease & $8.1(2,602)$ & $8.2(1,327)$ & $15.8(136)$ \\
\hline Chronic heart failure & $3.0(1,034)$ & $3.0(531)$ & $8.8(81)$ \\
\hline Stroke & $2.5(835)$ & $2.6(427)$ & $5.1(34)$ \\
\hline Cancer (any) & $7.1(2,910)$ & $7.1(1,464)$ & $10.9(107)$ \\
\hline Osteoarthritis & $19.0(7,527)$ & $19.2(3,878)$ & $28.2(300)$ \\
\hline Depression & $6.7(3,084)$ & $7.1(1,618)$ & $13.6(158)$ \\
\hline \multicolumn{4}{|c|}{ Number of chronic conditions, $\%(n)$} \\
\hline 0 & $56.0(24,783)$ & $55.5(12,577)$ & $38.6(475)$ \\
\hline 1 & $23.5(9,816)$ & $23.7(5,046)$ & $26.7(293)$ \\
\hline 2 & $12.0(4,559)$ & $12.1(2,338)$ & $18.1(164)$ \\
\hline$\geq 3$ & $8.5(2,875)$ & $8.7(1,479)$ & $16.7(155)$ \\
\hline
\end{tabular}

The results are weighted and refer to participants providing information for the variable of interest. Numbers of observations per variable $(n)$ are unweighted. Weighted percentage of missing values may vary for each variable and population sample ('pooled sample of GEDA 2009 and 2010, 'total sample of GEDA 2010, and 'subsample of participants with current asthma in GEDA 2010) for BMl status $\left(n^{1}=2.1, n^{2}=2.3, n^{3}=1.9\right)$, educational attainment $\left(n^{1}=0.2\right.$, $\left.n^{2}=0.2, n^{3}=0.2\right)$, smoking status $\left(n^{1}=0.0, n^{2}=0.0, n^{3}=0.0\right)$, diabetes mellitus $\left(n^{\prime}=0.2, n^{2}=0.2, n^{3}=0.5\right)$, hypertension $\left(n^{1}=0.4, n^{2}=0.4, n^{3}=0.4\right)$, coronary heart disease $\left(n^{1}=0.6, n^{2}=0.7, n^{3}=1.1\right)$, chronic heart failure $\left(n^{\prime}=0.9, n^{2}=0.9, n^{3}=1.5\right)$, stroke ( $\left.n^{\prime}=0.1, n^{2}=0.2, n^{3}=0.2\right)$, cancer (any) $\left(n^{1}=0.2, n^{2}=0.1, n^{3}=0.2\right)$, osteoarthritis $\left(n^{1}=1.0, n^{2}=1.0, n^{3}=1.0\right)$, depression $\left(n^{1}=0.3, n^{2}=0.3, n^{3}=0.8\right)$, number of chronic conditions $\left(n^{\prime}=3.5, n^{2}=3.3, n^{3}=5.3\right)$.

$\mathrm{BMI}=$ body mass index 


\section{Data collection and study variables}

Information on health status, medical history, health-related behaviours, socio-demographic, and anthropometric variables was collected based on computer-assisted telephone interviews. Based on a highly standardised protocol, interviewers who were trained and closely supervised according to the guidelines of the Behavioural Risk Factor Surveillance System of the Centers for Disease Control and Prevention (BRFSS) carried out the interviews. ${ }^{19}$ Participants were defined as having current asthma if they answered affirmatively to both of the consecutive questions about whether they had ever been told by a physician that they had asthma and whether asthma had been present within the last 12 months.

For the present analysis, data from the two consecutive national telephone health interview surveys (GEDA 2009 and 2010) were analysed. Persons with and without physician-diagnosed asthma in the past 12 months were compared with regard to eight concurrent high impact and/or high prevalence physician-diagnosed chronic conditions $^{11,12}$ : diabetes mellitus, hypertension, chronic heart failure, depression, osteoarthritis, and a lifetime diagnosis of stroke, coronary heart disease (with or without myocardial infarction), and cancer based on definitions that have previously been described in detail. ${ }^{20,21}$ An additive co-morbidity index was calculated as a fourlevel categorical variable $(0,1,2, \geq 3)$ adapted from Broemeling et al. and Prosser et al., ${ }^{4,12}$

In the subset of 1,136 individuals who participated in the 2010 GEDA survey and who reported a history of current asthma, information on the age of asthma onset and asthma-specific healthcare utilisation was obtained.2. The duration of asthma in years was calculated based on information on the current age and reported age of asthma onset. Asthma-related unscheduled care during the past 12 months was assessed using questions adapted from the BRFSS Asthma Call-back Survey section on healthcare utilisation, Adult Questionnaire. ${ }^{23}$ Unscheduled asthma care was differentiated into unscheduled inpatient care (any vs. no asthmarelated hospital or ED admission) and unscheduled outpatient care (any vs. no unscheduled doctor's office visit for urgent treatment of worsening asthma symptoms or an asthma attack).

Self-reported weight in kilograms was divided by height in metres squared in order to obtain the body mass index (BMI) of each survey participant. BMI level categories were classified according to criteria of the World Health Organization ${ }^{24,25}$ and defined as obese $\left(\geq 30 \mathrm{~kg} / \mathrm{m}^{2}\right)$, overweight $\left(\geq 25-<30 \mathrm{~kg} / \mathrm{m}^{2}\right)$ and non-overweight/nonobese $\left(<25 \mathrm{~kg} / \mathrm{m}^{2}\right)$. Educational attainment was defined according to the three-level International Standard Classification of Education (ISCED) and classified as primary, middle, or low. ${ }^{26}$ Smoking status was defined as 'current' (for reported daily or occasional smoking), 'former', and 'never', and chronological age groups were classified as $18-29,30-44,45-64$, and $\geq 65$ years. Analyses of co-morbidity patterns were performed between younger and older adults using a cut-off level of 55 years of age ( $<55$ vs. $\geq 55$ years) according to previous research..$^{4,9}$

\section{Statistical analyses}

All results were weighted to adjust for sampling probabilities and selective participation in order to represent the adult residential
Table 2. Main characteristics of the study population with respect to self-reported physician-diagnosed asthma: German telephone health interview survey German Health Update (GEDA) 2009 and 2010

\begin{tabular}{|c|c|c|c|}
\hline Characteristics & $\begin{array}{l}\text { Current } \\
\text { asthma } \\
(\mathrm{N}=2,242)\end{array}$ & $\begin{array}{l}\text { No current } \\
\text { asthma } \\
(\mathrm{N}=40,947)\end{array}$ & $p$ value* \\
\hline Gender & & & $<0.001$ \\
\hline Women, \% (n) & $58.6(1,429)$ & $51.0(23,092)$ & \\
\hline \multicolumn{4}{|l|}{ Age, in years } \\
\hline Mean (SD) & $52.5(18.2)$ & $48.8(17.9)$ & \\
\hline Range & $18-95$ & $18-100$ & \\
\hline Age groups, \% (n) & & & $<0.001$ \\
\hline $18-29$ years & $13.5(335)$ & $17.3(7,265)$ & \\
\hline 30-44 years & $21.7(566)$ & $25.9(11,477)$ & \\
\hline $45-64$ years & $33.5(825)$ & $32.7(14,576)$ & \\
\hline$\geq 65$ years & $31.3(516)$ & $24.1(7,629)$ & \\
\hline BMl status, \% (n) & & & $<0.001$ \\
\hline$<25 \mathrm{~kg} / \mathrm{m}^{2}$ & 39.1 (958) & $48.4(21,304)$ & \\
\hline $25-<30 \mathrm{~kg} / \mathrm{m}^{2}$ & $35.3(762)$ & $36.3(13,585)$ & \\
\hline$\geq 30 \mathrm{~kg} / \mathrm{m}^{2}$ & $25.7(480)$ & $15.3(5,222)$ & \\
\hline \multicolumn{2}{|l|}{ Educational attainment, \% (n) } & & $<0.001$ \\
\hline Primary & $26.5(259)$ & $21.8(3,932)$ & \\
\hline Middle & $55.4(1,212)$ & $55.6(20,703)$ & \\
\hline High & $18.1(765)$ & $22.6(16,255)$ & \\
\hline Smoking status, \% (n) & & & 0.013 \\
\hline Current & $28.5(616)$ & $29.9(11,866)$ & \\
\hline Former & $29.8(659)$ & $26.1(10,722)$ & \\
\hline Never & $41.7(967)$ & $44.0(18,343)$ & \\
\hline \multicolumn{4}{|l|}{ Health condition, \% (n) } \\
\hline Diabetes mellitus & $12.0(210)$ & $7.1(2,255)$ & $<0.001$ \\
\hline Hypertension & $37.9(734)$ & $25.8(9,219)$ & $<0.001$ \\
\hline Coronary heart disease & $16.7(269)$ & $7.5(2,318)$ & $<0.001$ \\
\hline Chronic heart failure & $8.2(146)$ & $2.7(885)$ & $<0.001$ \\
\hline Stroke & $5.5(81)$ & $2.3(751)$ & $<0.001$ \\
\hline Cancer (any) & $10.1(199)$ & $6.9(2,701)$ & $<0.001$ \\
\hline Osteoarthritis & $29.4(619)$ & $18.4(6,884)$ & $<0.001$ \\
\hline Depression & $13.3(304)$ & $6.3(2,769)$ & $<0.001$ \\
\hline \multicolumn{2}{|c|}{ Number of chronic conditions, $\%(n)$} & & $<0.001$ \\
\hline 0 & $38.9(938)$ & $57.0(23,796)$ & \\
\hline 1 & $26.2(579)$ & $23.4(9,214)$ & \\
\hline 2 & $17.1(317)$ & $11.7(4,224)$ & \\
\hline$\geq 3$ & $17.8(318)$ & $8.0(2,542)$ & \\
\hline
\end{tabular}

The results are weighted and refer to participants providing information for the variable of interest. Numbers of observations per variable $(n)$ are unweighted. Weighted percentage of missing values may vary for each variable and strata of current asthma' vs. no current asthma ${ }^{2}$ for BMI status $\left(n^{1}=2.0, n^{2}=2.1\right)$, educational attainment $\left(n^{\prime}=0.4, n^{2}=0.2\right)$, smoking status $\left(n^{\prime}=0.0, n^{2}=0.0\right)$, diabetes mellitus $\left(n^{1}=0.3, n^{2}=0.2\right)$, hypertension $\left(n^{1}=0.4, n^{2}=0.4\right)$, coronary heart disease $\left(n^{1}=0.8, n^{2}=0.6\right)$, chronic heart failure $\left(n^{1}=1.7, n^{2}=0.8\right)$, stroke $\left(n^{\prime}=0.2, n^{2}=0.1\right)$, cancer (any) $\left(n^{\prime}=0.2, n^{2}=0.2\right)$, depression $\left(n^{1}=0.4, n^{2}=0.3\right)$, osteoarthritis $\left(n^{1}=1.1, n^{2}=1.0\right)$, number of chronic conditions $\left(n^{1}=4.7, n^{2}=3.4\right)$. ${ }^{*} p$ values obtained from Rao-Scott $\chi^{2}$ test of independence with second-order adjustment. BMI=body mass index.

population of Germany, as previously described in detail. ${ }^{14,15}$ Data were analysed using IBM SPSS Statistics for Windows (version 20, Released 2011, Armonk, NY: IBM Corp.) with the complex sample module to ensure correct variance estimation in the presence of weights. For each variable, weighted proportions and unweighted $n$ 
refer to the number of participants who gave the information. The Rao-Scott $\chi^{2}$ test of independence with second-order adjustment was used to test globally for differences in the distribution of proportions. ${ }^{27}$ Besides age and gender, BMl categories, educational attainment, and smoking status as well as years of asthma duration were considered for adjustment as co-variables in multivariable logistic regression models. Missing values were excluded from the analyses and complete case analyses were performed. Based on two-sided tests, a significance level set at $p<0.05$ was regarded statistically significant.

\section{Results}

\section{Sample characteristics}

The characteristics of the whole sample of the pooled GEDA 2009 and 2010 surveys are summarised in Table 1. From the available pooled sample of 43,312 persons interviewed between 2008 and 2010, 2,242 people reported current physician-diagnosed asthma (5.3\%; 95\% confidence interval (Cl) 5.0\% to 5.6\%). The distribution of the main characteristics among those with and without asthma is shown in Table 2. Persons with current asthma were significantly more likely also to report other chronic conditions (Table 2). More than $60 \%$ of adults with current asthma reported at least one of the eight selected chronic conditions compared with less than half of those without current asthma.

\section{Relationship between asthma and co-morbidities}

A statistically independent association between asthma and selected co-morbidities generally persisted after controlling for possible confounders in multivariable analyses (Table 3). Independent associations with asthma were strongest for cardiovascular endorgan diseases and depression and least pronounced for a lifetime history of any cancer. Age-stratified analyses demonstrated that the independent pairwise associations were of similar direction and strength in both older and younger age groups ( $<55 \mathrm{vs}$. $\geq 55$ years of age), while the prevalence of co-morbidities strongly increased among older adults independent of current asthma (see Table S1 in Appendix available online at www.thepcrj.org).

\section{Relationship between the number of co-morbidities} and asthma outcomes

A total of 1,136 (5.3\%) study participants (737 women, 399 men) of the total GEDA 2010 survey sample of 22,050 persons aged $\geq 18$ years were included in the subset analysis. Among these, nearly every second person reported at least one asthma-related urgent care visit in the past 12 months (46.4\%; $95 \% \mathrm{Cl} 42.6 \%$ to $50.3 \%$ ). Overall, $9.0 \%$ (95\% Cl $7.1 \%$ to $11.5 \%$ ) reported at least one asthma-related hospitalisation and/or ED admission, ${ }^{22}$ and $45.3 \%$ (95\% Cl $41.5 \%$ to $49.2 \%$ ) reported at least one unscheduled outpatient care visit for asthma.

The distribution of the main characteristics according to the number of co-morbidities $(0,1,2, \geq 3)$ is shown in Table 4. Statistically significant differences were found according to age, educational attainment, and BMI status using the second-order adjusted Rao-Scott $\chi^{2}$ test of independence. Both outcome measures were associated with the number of co-morbidities and odds ratios (OR) rose with increasing number of chronic conditions irrespective of age, gender, BMI status, educational attainment, smoking status, and asthma duration (Table 5). In particular, a threefold higher chance of an asthma-related unscheduled inpatient care visit and a twofold higher chance of an unscheduled asthma-related outpatient care visit were estimated among individuals with $\geq 3$ chronic conditions compared with those without co-morbid conditions.

\section{Discussion}

\section{Main findings}

In this large national health interview study, a range of chronic conditions with high healthcare relevance was over-represented among adults with physician-diagnosed asthma compared with those without asthma. In particular, asthma was significantly associated with cardiovascular conditions and depression, irrespective of age. Among persons with asthma, the odds of any unscheduled asthma care visits (inpatient and outpatient) during the 12 months preceding the survey increased with increasing numbers of co-morbidities. Compared with persons without co-morbidities, those with multiple chronic conditions $(\geq 3)$ had a more than threefold higher chance of any asthma-related hospital/ED admission and a more than twofold higher chance of an unscheduled outpatient visit for urgent treatment of worsening asthma symptoms or an asthma attack.

\section{Strengths and limitations of this study}

We used data from a large national health survey covering a range

Table 3. Association between current asthma and selected chronic conditions (yes vs. no) among German adults aged $\geq 18$ years: German telephone health interview survey German Health Update (GEDA) 2009 and 2010

\begin{tabular}{|c|c|c|c|}
\hline Health condition & OR $(95 \% \mathrm{Cl}) *$ & OR $(95 \% \mathrm{Cl}) \dagger$ & OR $(95 \% \mathrm{Cl}) \ddagger$ \\
\hline Diabetes mellitus & 1.80 (1.48 to 2.18$)$ & $1.58(1.29$ to 1.94$)$ & 1.31 (1.06 to 1.63$)$ \\
\hline Hypertension & $1.76(1.56$ to 1.98$)$ & $1.63(1.42$ to 1.86$)$ & 1.47 (1.28 to 1.69$)$ \\
\hline Coronary heart disease & 2.46 (2.06 to 2.94$)$ & 2.34 (1.93 to 2.83$)$ & 2.14 (1.76 to 2.60$)$ \\
\hline Chronic heart failure & 3.22 (2.54 to 4.09$)$ & 2.84 (2.22 to 3.64$)$ & 2.74 (2.13 to 3.52$)$ \\
\hline Stroke & $2.48(1.82$ to 3.39$)$ & 2.16 (1.57 to 2.97$)$ & $2.12(1.54$ to 2.91$)$ \\
\hline Cancer (any) & $1.50(1.22$ to 1.84$)$ & $1.28(1.04$ to 1.58$)$ & 1.21 (0.98 to 1.50$)$ \\
\hline Depression & 2.27 (1.93 to 2.68$)$ & 2.18 (1.85 to 2.58$)$ & 2.06 (1.74 to 2.45$)$ \\
\hline
\end{tabular}


Table 4. Distribution of characteristics of the study population by number of chronic conditions among 1,136 adults with current asthma: German telephone health interview survey German Health Update (GEDA) 2010

\begin{tabular}{|c|c|c|c|c|c|}
\hline \multirow[b]{2}{*}{ Characteristic } & \multicolumn{4}{|c|}{ Number of chronic conditions } & \multirow[b]{2}{*}{$p$ value* } \\
\hline & $\begin{array}{l}0 \\
(\mathrm{~N}=475)\end{array}$ & $\begin{array}{l}1 \\
(N=293)\end{array}$ & $\begin{array}{l}2 \\
(N=164)\end{array}$ & $\begin{array}{l}>3 \\
(\mathrm{~N}=155)\end{array}$ & \\
\hline Gender & & & & & 0.608 \\
\hline Women, \% (n) & $57.7(295)$ & $64.1(191)$ & $62.3(109)$ & $62.3(105)$ & \\
\hline \multicolumn{6}{|l|}{ Age (years) } \\
\hline Mean (SD) & $40.2(15.3)$ & $51.9(16.4)$ & $60.3(13.3)$ & $68.2(11.8)$ & \\
\hline Age groups, \% (n) & & & & & $<0.001$ \\
\hline $18-29$ years & $27.2(128)$ & $10.8(34)$ & $0.8(3)$ & $0.4(1)$ & \\
\hline $30-44$ years & $37.4(176)$ & $19.7(64)$ & $12.1(25)$ & $1.8(4)$ & \\
\hline $45-64$ years & $26.7(134)$ & $45.5(146)$ & $43.7(83)$ & $31.1(56)$ & \\
\hline$\geq 65$ years & $8.8(37)$ & $23.9(49)$ & $43.4(53)$ & $66.8(94)$ & \\
\hline BMI status, \% (n) & & & & & $<0.001$ \\
\hline$<25 \mathrm{~kg} / \mathrm{m}^{2}$ & $52.6(256)$ & $34.2(113)$ & $25.6(45)$ & $29.5(51)$ & \\
\hline $25-<30 \mathrm{~kg} / \mathrm{m}^{2}$ & $35.2(148)$ & $41.7(109)$ & $40.5(66)$ & $28.9(48)$ & \\
\hline$\geq 30 \mathrm{~kg} / \mathrm{m}^{2}$ & $12.2(56)$ & $24.1(69)$ & $33.9(51)$ & $41.6(53)$ & \\
\hline Educational attainment, \% (n) & & & & & 0.006 \\
\hline Primary & $20.9(48)$ & $24.5(27)$ & $34.3(21)$ & $34.1(22)$ & \\
\hline Middle & $54.6(239)$ & $59.7(174)$ & $55.7(101)$ & $52.1(81)$ & \\
\hline High & $24.5(187)$ & $15.8(92)$ & $9.9(42)$ & $13.9(52)$ & \\
\hline Smoking status, \% (n) & & & & & 0.089 \\
\hline Current & $32.7(141)$ & $30.2(84)$ & $24.8(44)$ & $24.3(36)$ & \\
\hline Former & $23.9(116)$ & $36.4(105)$ & $33.8(54)$ & $35.0(47)$ & \\
\hline Never & $43.4(218)$ & $33.4(104)$ & $41.5(66)$ & $40.7(72)$ & \\
\hline Asthma duration, years & $(\mathrm{N}=450)$ & $(\mathrm{N}=281)$ & $(\mathrm{N}=159)$ & $(\mathrm{N}=145)$ & \\
\hline Mean (SD) & $16.9(13.4)$ & $21.5(18.1)$ & $20.7(18.8)$ & $19.6(18.4)$ & \\
\hline
\end{tabular}

Table 5. Association of the number of co-morbidities $(1,2, \geq 3$ vs. 0$)$ with asthma outcome measures among 1,136 adults with current asthma: German telephone health interview survey German Health Update (GEDA) 2010

\begin{tabular}{lllll} 
Number of chronic conditions & $\%(\mathrm{n} / \mathrm{N})$ & OR $(95 \% \mathrm{Cl})^{*}$ & OR $(95 \% \mathrm{Cl}) \dagger$ & OR $(95 \% \mathrm{Cl}) \neq$ \\
\hline \multicolumn{2}{l}{ Any asthma-related unscheduled inpatient care visit } & \multicolumn{3}{l}{} \\
\hline 0 & $9.5(33 / 474)$ & Reference & Reference & Reference \\
\hline 1 & $6.8(24 / 293)$ & $0.70(0.34$ to 1.42$)$ & $0.96(0.43$ to 2.11$)$ & $1.09(0.53$ to 2.24$)$ \\
\hline 2 & $8.5(18 / 163)$ & $0.88(0.42$ to 1.85$)$ & $1.49(0.62$ to 3.57$)$ & $1.50(0.63$ to 3.55$)$ \\
\hline$\geq 3$ & $14.0(19 / 155)$ & $1.54(0.73$ to 3.25$)$ & $2.90(1.17$ to 7.22$)$ & $3.40(1.39$ to 8.31$)$ \\
\hline Any asthma-related unscheduled outpatient care visit & & & \\
\hline 0 & $42.0(177 / 471)$ & Reference & Reference & Reference \\
\hline 1 & $39.3(127 / 290)$ & $0.89(0.61$ to 1.30$)$ & $0.95(0.64$ to 1.41$)$ & $1.07(0.72$ to 1.59$)$ \\
\hline 2 & $51.6(82 / 160)$ & $1.47(0.91$ to 2.37$)$ & $1.65(0.98$ to 2.79$)$ & $1.86(1.09$ to 3.16$)$ \\
\hline$\geq 3$ & $54.3(76 / 149)$ & $1.64(1.00$ to 2.69$)$ & $1.95(1.10$ to 3.45$)$ & $2.32(1.30$ to 4.14$)$ \\
\hline
\end{tabular}

$\%$, weighted prevalence of asthma outcomes refers to participants providing information for the variable of interest. Numbers of observations per variable ( $\mathrm{n}$ ) are unweighted and may vary due to the number of missing values.

Odds ratio (OR) and $95 \%$ confidence interval $(95 \% \mathrm{Cl})$ obtained from multivariable logistic regression analyses: ${ }^{*}$ Crude OR. + OR adjusted for age group and gender. ‡OR adjusted for age group, gender, body mass index categories, educational attainment, smoking status, and asthma duration

of chronic health conditions. Our analyses were based on individual level data that do not only comprise information on the utilisation of asthma-related healthcare services, but also on individual characteristics such as anthropometric, socio-demographic and behavioural factors, and the age of asthma onset. By assessing the association of major chronic disease co-morbidity with unscheduled asthma care outcomes, our findings extend previous research addressing the effects of co-morbidity on the utilisation of nonspecific inpatient and outpatient healthcare services, ${ }^{5}$ on asthmaspecific HRQoL, ${ }^{8}$ and on asthma symptoms and/or attacks. ${ }^{10}$

We assessed self-reported medical diagnoses cross-sectionally. Although this is considered an established method for assessing 
morbidity in large epidemiological studies, ${ }^{20}$ some methodological limitations need to be discussed. First, misclassification bias is an issue. A questionnaire-based definition of physician-diagnosed asthma in epidemiological studies is considered to have a high specificity and positive predictive value, ${ }^{28}$ and adult patients were found to report physician-diagnosed asthma accurately. ${ }^{29}$ Nevertheless, underdiagnosis of asthma cannot be excluded, particularly among elderly persons..$^{30-32}$ Moreover, it is conceivable that confounding of asthma and chronic obstructive pulmonary disease (COPD) might occur, especially with respect to older age. ${ }^{33,34}$ However, current evidence indicates that diagnostic confusion of both conditions in primary care has decreased in recent years, which might be due to better guideline implementation in clinical practice. ${ }^{35}$ On the other hand, COPD might develop and overlap, particularly among older individuals with asthma. ${ }^{36,37}$ COPD was not assessed in the present study and, hence, we could not disentangle the relationship between the two conditions. Still, the relationships between asthma and the co-morbidities were consistent in older and younger adults and the associations with asthma outcomes were also independent of years of asthma duration.

Second, it is conceivable that non-respiratory co-morbidities causing respiratory symptoms such as chronic heart failure might be missed among individuals with asthma. ${ }^{32}$ Detection bias might therefore have resulted in an underestimation of the actual effect size in our results. On the other hand, detection bias might have led to an overestimation of the effect of the association with asthma and health conditions comprising relevant proportions of asymptomatic cases such as diabetes. However, a positive association between asthma and diabetes has also been reported from longitudinal assessments. ${ }^{38,39}$

Finally, we could not perform non-response analyses based on information collected for non-responders and responders. However, all results were weighted to adjust for sampling probabilities and selective participation in order to assure representativeness at the population level and increase the generalisability of the present findings to the adult population of Germany. ${ }^{14,15}$

\section{Interpretation of findings in relation to previously published research}

\section{a) Association of co-morbidities with asthma}

The patterns and strengths of the relationships between asthma and co-morbidities observed in our study are essentially in line with reports from two large population-based surveys and a large health administrative data analysis. ${ }^{4,9,10}$ Specifically, our observation that more than $60 \%$ of adults with asthma reported at least one concurrent disorder and $18 \%$ reported at least three concurrent disorders of high public health impact agrees very well with previous estimates obtained from an analysis of a large population-based administrative health database. ${ }^{4}$ Our findings on cross-sectional relationships between asthma and co-morbidities are supported by results from previous longitudinal studies. ${ }^{38-41}$

In the present study, asthma was particularly related to cardiovascular diseases and depression, with ORs increased more than twofold. Moderate associations were found for other conditions, and were least pronounced for a lifetime history of any cancer. Adams et al. also reported approximately twofold higher ORs of self-reported stroke or heart disease in association with asthma. In this previous study, asthma was moderately and significantly associated with arthritis and cancer $^{9}$ while a positive relation between asthma and diabetes was not statistically significant. Zhang et al. previously showed considerable associations of asthma with mental health conditions with more than twofold higher ORs, and demonstrated moderately increased ORs for selfreported stroke, heart disease, high blood pressure, diabetes, and arthritis/ rheumatism. ${ }^{10}$ In agreement with our results, no significant association between asthma and cancer was observed in this previous study. Findings on the relationships between asthma and co-morbidities based on administrative health service data are also consistent with our results. ${ }^{4}$ Moreover, longitudinal associations of asthma with depression, cardiovascular diseases, and diabetes have also been observed in studies of the relationship between asthma and a single co-morbidity. ${ }^{38-41}$ These associations may be due to the fact that asthma and other chronic conditions share common risk factors such as obesity or smoking. As has been discussed for COPD, there may be an early interaction between disease processes on the basis of chronic inflammation. ${ }^{42-44}$ Our observation that the strength of the association between asthma and chronic co-morbidities was of similar direction and strength in both older and younger individuals, while the prevalence of co-morbidities strongly increased among older adults independent of current asthma is supported by results from a previous large study of asthma co-morbidity including age-stratified analyses. Similar to the results of the present study, this previous study showed an age-related increase in the prevalence of cardiovascular and hypertensive disease, depression and diabetes, while the strength of the associations between asthma and these conditions remained stable across age groups. ${ }^{3,6}$

\section{b) Association of co-morbidities with asthma \\ outcomes}

In the present study the chance of asthma-related hospital/ED admissions and of unscheduled outpatient visits for urgent treatment of worsening asthma symptoms or an asthma attack increased with the number of co-morbidities. In particular, persons with asthma and $\geq 3$ co-morbid conditions had a significantly twoto threefold higher chance of adverse outcomes compared to persons with asthma who had no concurrent chronic health condition, independent of age, gender, BMI status, educational attainment, smoking status, and asthma duration. This is in line with previous analyses based on an administrative health database which showed that among adults with asthma compared to those without co-morbidity was associated with a significant proportion of overall non-specific hospitalisations, emergency room visits, and ambulatory care visits. ${ }^{5}$ Similarly, in two other population-based surveys, a negative effect of the presence of major chronic conditions on asthma-specific $\mathrm{HRQOL}^{8}$ as well as on asthma symptoms and/or attacks ${ }^{10}$ was observed.

There are several possible explanations for the association between asthma co-morbidity and adverse asthma outcomes observed here and previously. First, the association could be due to interactive disease processes. Systemic inflammation has not only 
been related to several chronic diseases such as cardiovascular endorgan disease and diabetes, but might also be common among adults with asthma. ${ }^{42,45}$ Interactive inflammatory processes have recently been suggested to contribute to a higher risk of asthma exacerbations in individuals with higher levels of non-asthma-related visits to the general practitioner. ${ }^{46}$ However, the relationship between systemic inflammation and co-morbidity in asthma remains to be elucidated. ${ }^{42}$

Second, the presence of multiple chronic conditions could also influence patient self-management. ${ }^{47}$ In particular, several perceived barriers to self-care have been identified by authors of a qualitative study among adults aged $\geq 31$ years who had two or more of the following chronic conditions: osteoarthritis, coronary artery disease, COPD, asthma, diabetes, hypertension, or congestive heart failure. ${ }^{47}$ In this previous study, participants were facing competing demands between self-management tasks for one condition and self-care of another (e.g. difficulties in adhering to exercise for the management of diabetes in the presence of respiratory conditions). Moreover, in this previous study, drug treatment for one condition was found to increase the morbidity of another due to therapeutic or adverse effects. ${ }^{47}$ Thus, thirdly, an additive effect of co-morbidity on asthma outcomes might also reflect drug effects including drug-drug interactions. Several drugs that are commonly used for the treatment of hypertension, cardiovascular conditions or osteoarthritis (e.g. non-steroidal anti-inflammatory drugs or betaadrenergic blockers) can influence asthma control. ${ }^{48,49}$ As the number of drugs increases and the medication regimen becomes more complex, barriers to adherence and the risk of drug interactions and adverse drug effects can also increase. ${ }^{50,51}$

\section{Implications for future research, policy and practice}

Based on data from a large national health survey, we observed that chronic conditions that are highly prevalent in the general population and that have a substantial impact on the healthcare system commonly co-exist with asthma, irrespective of age. To date, this has been largely disregarded among adults with asthma and raises the question whether there is an early interaction between disease processes. Longitudinal epidemiological and experimental research needs to further clarify the mechanisms of more than chance cooccurrence in order to identify potential preventive strategies. One possibility that might be particularly relevant to clinical practice is the role of common risk factors in asthma co-morbidity. In order to reduce the burden of co-morbidity in later life, early interventions targeting common risk factors might be particularly relevant for young persons with asthma. In addition, the findings of our population-based study also highlight the need for considering co-morbidities in secondary and tertiary preventive care of patients with asthma.

The results of our population-based study provide evidence that multiple co-morbid conditions are common among adults with asthma. It can therefore be assumed that a significant number of individuals in the general asthma population face complex healthcare needs. So far, this reality has received little attention in clinical guidelines. As demonstrated in the present analysis, multiple comorbid conditions relate to an adverse asthma outcome. Thus, future research needs to investigate the mechanisms by which specific patterns of co-morbidity influence the clinical course and the outcome of asthma patients. Our findings further underline the need for interventions tailored to specific disease combinations in clinical practice. With a lack of sufficient evidence it has proved difficult to adapt evidence-based clinical guideline recommendations accordingly. ${ }^{52}$ Apart from additive effects resulting from the interaction between disease processes or drug interactions, the effects of multiple co-morbidities on patient self-management as well as other aspects of patient complexity such as depression and social factors need to be considered. ${ }^{53,54}$

\section{Conclusions}

National health survey data indicate that asthma co-morbidity has a high public health impact and needs to be adequately considered in clinical guidelines for the management of older as well as younger adults with asthma. Further research is needed to gain insight into the mechanisms underlying the observed independent association between asthma and various other chronic diseases - in particular cardiovascular conditions and depression - and to identify the specific healthcare needs of patients with asthma in the presence of specific co-morbidities.

\section{Handling editor Maureen George Statistical review Gopal Netuveli}

Conflicts of interest The authors declare that they have no conflicts of interest in relation to this article.

Contributorship HS, UL, and CS participated in the concept and design of the study. All authors participated in the design of the analysis plan and the interpretation of the data. HS, UL, and CS analysed the data and drafted the manuscript. UL, CS, and TK critically revised the manuscript and supervised HS. All authors read and approved the final manuscript.

Funding The study was funded by the German Federal Ministry of Health and the Robert Koch Institute.

\section{References}

1. Gijsen R, Hoeymans N, Schellevis FG, Ruwaard D, Satariano WA, van den Bos GA. Causes and consequences of comorbidity: a review. J Clin Epidemiol 2001; 54(7):661-74. http://dx.doi.org/10.1016/S0895-4356(00)00363-22

2. Charlson M, Charlson RE, Briggs W, Hollenberg J. Can disease management target patients most likely to generate high costs? The impact of comorbidity. J Gen Intern Med 2007;22(4):464-9. http://dx.doi.org/10.1007/s11606-007-0130-7

3. Boulet LP, Boulay ME. Asthma-related comorbidities. Expert Rev Respir Med 2011; 5(3):377-93. http://dx.doi.org/10.1586/ers.11.34

4. Prosser $\mathrm{R}$, Carleton B, Smith A. The comorbidity burden of the treated asthma patient population in British Columbia. Chronic Dis Can 2010;30(2):46-55.

5. Gershon AS, Wang C, Guan J, To T. Burden of comorbidity in individuals with asthma. Thorax 2010;65(7):612-18. http://dx.doi.org/10.1136/thx.2009.131078

6. Cazzola M, Calzetta L, Bettoncelli G, Novelli L, Cricelli C, Rogliani P. Asthma and comorbid medical illness. Eur Respir J 2011;38(1):42-9. http://dx.doi.org/10.1183/09031936.00140310

7. Gershon AS, Guan J, Wang C, Victor JC, To T. Describing and quantifying asthma comorbidity: a population study. PloS One 2012;7(5):e34967. http://dx.doi.org/10.1371/journal.pone.0034967

8. Wijnhoven HA, Kriegsman DM, Hesselink AE, de Haan M, Schellevis FG. The influence of co-morbidity on health-related quality of life in asthma and COPD patients. Respir Med 2003;97(5):468-75. http://dx.doi.org/10.1053/rmed.2002.1463

9. Adams RJ, Wilson DH, Taylor AW, et al. Coexistent chronic conditions and asthma quality of life: a population-based study. Chest 2006;129(2):285-91. http://dx.doi.org/10.1378/chest.129.2.285

10. Zhang T, Carleton BC, Prosser RJ, Smith AM. The added burden of comorbidity in patients with asthma. J Asthma 2009;46(10):1021-6. http://dx.doi.org/10.3109/02770900903350473 
11. Broemeling AM, Watson D, Black C. Chronic conditions and co-morbidity among residents of British Columbia. Vancouver, BC: Centre for Health Services and Policy Research, The University of British Columbia, 2005.

12. Broemeling AM, Watson DE, Prebtani F. Population patterns of chronic health conditions, co-morbidity and healthcare use in Canada: implications for policy and practice. Healthc Q 2008;11(3):70-6. http://dx.doi.org/10.12927/hcq.2008.19859

13. Kurth BM, Lange $C$, Kamtsiuris $P$, Holling $H$. [Health monitoring at the Robert Koch Institute. Status and perspectives]. Bundesgesundheitsblatt, Gesundheitsforschung, Gesundheitsschutz 2009;52(5):557-70. http://dx.doi.org/10.1007/s00103-009-0843-3

14. Robert Koch-Institut. Daten und Fakten: Ergebnisse der Studie 'Gesundheit in Deutschland aktuell 2009'. Berlin: Robert Koch-Institut, 2011.

15. Robert Koch-Institut. Daten und Fakten: Ergebnisse der Studie 'Gesundheit in Deutschland aktuell 2010'. Berlin: Robert Koch-Institut, 2012.

16. Gabler S, Haeder S. Idiosyncrasies in telephone sampling - the case of Germany. Int J Public Opin Res 2002;14(3):339-45. http://dx.doi.org/10.1093/ijpor/14.3.339

17. Salmon CT, Nichols JS. The next-birthday method of respondent selection. Public Opin Q 1983;47(2):270-6. http://dx.doi.org/10.1086/268785

18. American Association for Public Opinion Research. Standard definitions: final dispositions of case codes and outcome rates for surveys, 2009. Available from: http://www.aapor.org/Content/NavigationMenu/ResourcesforResearchers/StandardD efinitions/StandardDefinitions2009new.pdf

19. Centers for Disease Control and Prevention (CDC). Behavioral risk factor surveillance system 2009. US Department of Health and Human Services, Centers for Disease Control and Prevention, 2010.

20. Fuchs J, Busch M, Lange C, Scheidt-Nave C. Prevalence and patterns of morbidity among adults in Germany. Results of the German telephone health interview survey German Health Update (GEDA) 2009. Bundesgesundheitsblatt, Gesundheitsforschung, Gesundheitsschutz 2012;55(4):576-86.

http://dx.doi.org/10.1007/s00103-012-1464-9

21. Du Y, Heidemann C, Gosswald A, Schmich P, Scheidt-Nave C. Prevalence and comorbidity of diabetes mellitus among non-institutionalized older adults in Germany: results of the national telephone health interview survey 'German Health Update (GEDA)' 2009. BMC Public Health 2013;13(1):166.

http://dx.doi.org/10.1186/1471-2458-13-166

22. Steppuhn H, Langen U, Scheidt-Nave C, Keil T. Major comorbid conditions in asthma and association with asthma-related hospitalizations and emergency department admissions in adults: results from the German national health telephone interview survey (GEDA) 2010. BMC Pulm Med 2013;13(1):46.

http://dx.doi.org/10.1186/1471-2466-13-46

23. Akinbami $\sqcup$, Sullivan SD, Campbell JD, et al. Asthma outcomes: healthcare utilization and costs. J Allergy Clin Immunol 2012;129(3 Suppl):S49-64. http://dx.doi.org/10.1016/j.jaci.2011.12.984

24. World Health Organization. Obesity and overweight. Fact Sheet N.311 (updated March 2013; cited 16 April 2013). Available from: http://www.who.int/mediacentre/ factsheets/fs311/en/index.html\#

25. World Health Organization. Obesity: preventing and managing the global epidemic. Report of a WHO consultation. Geneva: World Health Organization, 2000.

26. Schroedter JH, Lechert $Y$, Lüttinger P. Die Umsetzung der Bildungsskala ISCED-1997 für die Volkszählung 1970, die Mikrozensus- Zusatzerhebung 1971 und die Mikrozensen 1976-2004. ZUMA-Methodenbericht. 2006/08. Mannheim: ZUMA, 2006.

27. Lehtonen R, Pakinen E. Practical method for design and analyses of complex surveys. Chichester, UK: John Wiley and Sons, 2004.

28. Kilpelainen M, Terho EO, Helenius $H$, Koskenvuo $M$. Validation of a new questionnaire on asthma, allergic rhinitis, and conjunctivitis in young adults. Allergy 2001;56(5):377-84. http://dx.doi.org/10.1034/j.1398-9995.2001.056005377.x

29. Abramson MJ, Schattner RL, Sulaiman ND, Del Colle EA, Aroni R, Thien F. Accuracy of asthma and COPD diagnosis in Australian general practice: a mixed methods study. Prim Care Respir J 2012;21(2):167-73. http://dx.doi.org/10.4104/pcrj.2011.00103

30. Barnard A, Pond CD, Usherwood TP. Asthma and older people in general practice. Med J Aust 2005;183(1 Suppl):S41-3.

31. Enright PL, McClelland RL, Newman AB, Gottlieb DJ, Lebowitz MD. Underdiagnosis and undertreatment of asthma in the elderly. Cardiovascular Health Study Research Group. Chest 1999;116(3):603-13. http://dx.doi.org/10.1378/chest.116.3.603

32. Gibson PG, McDonald VM, Marks GB. Asthma in older adults. Lancet
2010;376(9743):803-13. http://dx.doi.org/10.1016/S0140-6736(10)61087-2

33. Bellia V, Battaglia S, Catalano F, et al. Aging and disability affect misdiagnosis of COPD in elderly asthmatics: the SARA study. Chest 2003;123(4):1066-72. http://dx.doi.org/10.1378/chest.123.4.1066

34. Al-Kassimi FA, Abba AA, Al-Hajjaj MS, Alhamad EH, Raddaoui E, Shaikh SA. Asthma masquerading as chronic obstructive pulmonary disease: a study of smokers fulfilling the GOLD definition of chronic obstructive pulmonary disease. Respiration 2011;82(1):19-27. http://dx.doi.org/10.1159/000323075

35. Melbye H, Drivenes E, Dalbak LG, Leinan T, Hoegh-Henrichsen S, Ostrem A. Asthma, chronic obstructive pulmonary disease, or both? Diagnostic labeling and spirometry in primary care patients aged 40 years or more. Int J Chron Obstruct Pulmon Dis 2011;6:597-603. http://dx.doi.org/10.2147/COPD.S25955

36. Silva GE, Sherrill DL, Guerra S, Barbee RA. Asthma as a risk factor for COPD in a longitudinal study. Chest 2004;126(1):59-65. http://dx.doi.org/10.1378/chest.126.1.59

37. van der Molen T. Co-morbidities of COPD in primary care: frequency, relation to COPD, and treatment consequences. Prim Care Respir J 2010;19(4):326-34 http://dx.doi.org/10.4104/pcri.2010.00053

38. Ehrlich SF, Quesenberry CP, Jr., Van Den Eeden SK, Shan J, Ferrara A. Patients diagnosed with diabetes are at increased risk for asthma, chronic obstructive pulmonary disease, pulmonary fibrosis, and pneumonia but not lung cancer. Diabetes Care 2010;33(1):55-60. http://dx.doi.org/10.2337/dc09-0880

39. Mueller NT, Koh WP, Odegaard AO, Gross MD, Yuan JM, Pereira MA. Asthma and the risk of type 2 diabetes in the Singapore Chinese Health Study. Diabetes Res Clin Pract 2013;99(2):192-9. http://dx.doi.org/10.1016/j.diabres.2012.11.019

40. Iribarren C, Tolstykh IV, Miller MK, Sobel E, Eisner MD. Adult asthma and risk of coronary heart disease, cerebrovascular disease, and heart failure: a prospective study of 2 matched cohorts. Am J Epidemiol 2012;176(11):1014-24. http://dx.doi.org/10.1093/aje/kws181

41. Thomas M, Bruton A, Moffat M, Cleland J. Asthma and psychological dysfunction. Prim Care Respir J 2011;20(3):250-6. http://dx.doi.org/10.4104/pcrj.2011.00058

42. Magnussen $\mathrm{H}$, Watz $\mathrm{H}$. Systemic inflammation in chronic obstructive pulmonary disease and asthma: relation with comorbidities. Proc Am Thorac Soc 2009; 6(8):648-51. http://dx.doi.org/10.1513/pats.200906-053DP

43. Barnes PJ, Celli BR. Systemic manifestations and comorbidities of COPD. Eur Respir J 2009;33(5):1165-85. http://dx.doi.org/10.1183/09031936.00128008

44. Wouters EF, Reynaert NL, Dentener MA, Vernooy JH. Systemic and local inflammation in asthma and chronic obstructive pulmonary disease: is there a connection? Proc Am Thorac Soc 2009;6(8):638-47. http://dx.doi.org/10.1513/ pats.200907-073DP

45. Ford ES. Asthma, body mass index, and C-reactive protein among US adults. J Asthma 2003;40(7):733-9. http://dx.doi.org/10.1081/JAS-120023497

46. Hyland ME, Whalley B, Halpin DM, et al. Frequency of non-asthma GP visits predicts asthma exacerbations: an observational study in general practice. Prim Care Respir J 2012;21(4):405-11. http://dx.doi.org/10.4104/pcrj.2012.00061

47. Bayliss EA, Steiner JF, Fernald DH, Crane LA, Main DS. Descriptions of barriers to selfcare by persons with comorbid chronic diseases. Ann Fam Med 2003;1(1):15-21. http://dx.doi.org/10.1370/afm.4

48. Covar RA, Macomber BA, Szefler SJ. Medications as asthma triggers. Immunol Allergy Clin North Am 2005;25(1):169-90. http://dx.doi.org/10.1016/j.iac.2004.09.009

49. Reed CE. Asthma in the elderly: diagnosis and management. J Allergy Clin Immunol 2010;126(4):681-7; quiz 688-9. http://dx.doi.org/10.1016/j.jaci.2010.05.035

50. Johnell K, Klarin I. The relationship between number of drugs and potential drugdrug interactions in the elderly: a study of over 600,000 elderly patients from the Swedish Prescribed Drug Register. Drug Saf 2007;30(10):911-18.

51. DeSevo G, Klootwyk J. Pharmacologic issues in management of chronic disease. Prim Care 2012;39(2):345-62. http://dx.doi.org/10.1016/j.pop.2012.03.007

52. Guthrie B, Payne K, Alderson P, McMurdo ME, Mercer SW. Adapting clinical guidelines to take account of multimorbidity. BMJ 2012;345:e6341. http://dx.doi.org/10.1136/bmj.e6341

53. Valderas JM, Starfield B, Sibbald B, Salisbury C, Roland M. Defining comorbidity: implications for understanding health and health services. Ann Fam Med 2009: 7(4):357-63. http://dx.doi.org/10.1370/afm.983

54. Mercer SW, Gunn J, Bower P, Wyke S, Guthrie B. Managing patients with mental and physical multimorbidity. BMJ 2012;345:e5559.

http://dx.doi.org/10.1136/bmj.e5559 
Appendix: Table S1 Association between current asthma and selected chronic conditions among German adults by age category (<55 vs. $\geq 55$ years): German telephone health interview surveys (GEDA) 2009 and 2010

\begin{tabular}{|c|c|c|c|c|c|c|}
\hline \multirow[b]{3}{*}{ Health condition } & \multicolumn{3}{|c|}{$<55$ years of age } & \multicolumn{3}{|c|}{$\geq 55$ years of age } \\
\hline & \multicolumn{2}{|c|}{ Asthma bronchiale } & \multirow{2}{*}{$\begin{array}{l}\text { OR } \\
(95 \% \mathrm{Cl})\end{array}$} & \multicolumn{2}{|c|}{ Asthma bronchiale } & \multirow{2}{*}{$\begin{array}{l}\text { OR } \\
(95 \% \mathrm{Cl})\end{array}$} \\
\hline & Yes & No & & Yes & No & \\
\hline Diabetes mellitus & 5.1 & 2.3 & 1.70 (1.16 to 2.50$)$ & 19.7 & 14.9 & $1.18(0.92$ to 1.53$)$ \\
\hline Hypertension & 19.3 & 11.5 & $1.55(1.26$ to 1.91$)$ & 58.4 & 49.0 & $1.38(1.15$ to 1.66$)$ \\
\hline Coronary heart disease & 4.5 & 1.9 & $2.13(1.44$ to 3.14$)$ & 30.4 & 16.9 & $2.09(1.68$ to 2.60$)$ \\
\hline Chronic heart failure & 2.3 & 0.7 & 2.77 (1.54 to 4.98$)$ & 14.9 & 6.0 & $2.67(2.01$ to 3.54$)$ \\
\hline Stroke & 1.8 & 0.6 & 2.23 (1.11 to 4.47$)$ & 9.6 & 5.1 & $2.02(1.41$ to 2.91$)$ \\
\hline Cancer (any) & 4.8 & 2.9 & 1.58 (1.13 to 2.20$)$ & 15.8 & 13.6 & $1.08(0.83$ to 1.41$)$ \\
\hline Osteoarthritis & 13.8 & 8.1 & 1.60 (1.29 to 1.99$)$ & 46.7 & 35.2 & $1.52(1.26$ to 1.82$)$ \\
\hline Depression & 13.9 & 6.1 & 2.21 (1.78 to 2.75$)$ & 12.6 & 6.6 & 1.94 (1.48 to 2.56$)$ \\
\hline
\end{tabular}

